\section{Post-feeding hyperammonaemia in patients with transjugular intrahepatic portosystemic shunt and liver cirrhosis: role of small intestinal ammonia release and route of nutrient administration}

\author{
M Plauth, A-E Roske, P Romaniuk, E Roth, R Ziebig, H Lochs
}

Despite the emergence of other potential pathogenetic mechanisms, hyperammonaemia is still regarded as a relevant factor in the pathogenesis of hepatic encephalopathy. The pathogenetic concept that metabolism of colonic bacteria is the major source of the portal venous ammonia $\operatorname{load}^{12}$ failed to provide a full understanding of phenomena such as the "germ free paradox". This term was coined after the observation that hepatic coma and hyperammonaemia occurred in germ free animals following construction of an Eck fistula or after hepatectomy. ${ }^{34}$ These phenomena, however, could be explained by the observation that the small intestinal mucosa normally extracts glutamine from arterial blood for metabolism of enterocytes and releases considerable quantities of ammonia into the portal vein. ${ }^{5}$ From studies in catheterised pigs or dogs, it was estimated that amino acid metabolism of the small intestinal mucosa is a relevant source of portal ammonia that cannot be suppressed by antibiotics or lactulose..$^{7-9}$

Therapeutic interventions aimed at reduction in portal pressure by surgical or transjugular construction of a portosystemic shunt are accompanied by an increase in the frequency and/or severity of episodes of hepatic encephalopathy. ${ }^{10-14}$ We hypothesised that following a transjugular intrahepatic portosystemic shunt (TIPS), small intestinal ammonia production may lead to a higher degree of systemic hyperammonaemia when nutrition is given by the enteral rather than the parenteral route. This could be clinically relevant as enteral nutrition has generally been regarded as preferable to parenteral nutrition in patients with decompensated chronic liver disease. ${ }^{15}$ Furthermore, because of the poor accessibility of the portal or mesenteric veins, human data on intestinal glutamine and ammonia metabolism are available only for the fasting state during elective abdominal surgery without infusion of substrates ${ }^{16-20}$; there are no data under postprandial or parenterally fed conditions in patients with liver cirrhosis. Therefore, we have investigated in patients with TIPS whether the small intestine is a relevant source for systemic post-feeding hyperammonaemia and to what extent post-feeding hyperammonaemia

Abbreviations used in this paper: $\mathrm{AA}$, amino acid; ALD, alcoholic liver disease; AUC, area under the curve; PBC, primary biliary cirrhosis; SMV, superior mesenteric vein; TIPS, transjugular intrahepatic portosystemic shunt.
Hepatologie und

Endokrinologie, Campus

Charité Mitte, D-10098

Berlin, Germany

Accepted for publication 25 November 1999
Keywords: hepatic encephalopathy; intestinal metabolism; ammonia; glutamine; enteral nutrition; parenteral nutrition 
is affected by the supply of nitrogenous nutrients via the enteral compared with the parenteral route. $^{21}$

\section{Methods}

PATIENTS

In 16 consecutive patients with liver cirrhosis of alcoholic or autoimmune aetiology (table 1), a TIPS was inserted for refractory ascites $(n=1)$ or for recurrent variceal bleeding $(n=15)$. Patients were studied either on the day of TIPS insertion $(n=5 / 8$ in the enteral group and $\mathrm{n}=3 / 8$ in the parenteral group) or during routine portography for examination of TIPS patency. All patients were in a stable condition $(\geqslant 15$ days since the last haemorrhage, transaminase $<3$ times the upper limit of normal). Before the study, an oral decontamination protocol was instituted for 72 hours, consisting of tobramycin $80 \mathrm{mg}$ four times daily, colistin $100 \mathrm{mg}$ four times daily and amphotericin B $500 \mathrm{mg}$ four times daily to reduce ammonia production from intestinal bacteria. ${ }^{22}$ All patients gave written informed consent to participate in the study which was reviewed by the Charité ethics committee and which conformed to the guidelines of the 1975 Declaration of Helsinki.

\section{CATHETERISATION}

To measure small intestinal ammonia release, immediately after TIPS construction or after TIPS angiography, the tip of a $5 \mathrm{~F}$ multipurpose angiographic catheter was placed in the superior mesenteric vein, 3-4 cm before the junction with the splenic vein, and left in situ until the end of the study. During the study and subsequent angiographic studies there was no evidence of thrombotic sequelae from mesenteric venous catheterisation. An indwelling catheter (LeaderCath, Vygon, 115/09, 20G, 8 $\mathrm{cm}, 0.6-0.9 \mathrm{~mm}$ ) was placed in the left radial artery. All catheters were rinsed with sterile saline between sampling. A fine bore nasoduodenal tube (Frekasoft 8F, Fresenius, Oberursel, Germany) was inserted under fluoroscopic control immediately before the angiographic procedure and controlled for correct position afterwards.

\section{MEDICATION}

During the TIPS procedure, fentanyl or alfentanil was given for analgesia and midazolam for sedation. Immediately after TIPS, a bolus dose of heparin 5000 IU was given intravenously. After transfer to the metabolic ward a constant

Table 1 Patient characteristics (mean (SEM) or number)

\begin{tabular}{lll}
\hline & Enteral $(n=8)$ & Parenteral $(n=8)$ \\
\hline Age (years) & $40.0(2.4)$ & $48.9(3.1)$ \\
Weight (kg) & $83.0(4.9)$ & $76.0(2.0)$ \\
Height (cm) & $182(2)$ & $176(2)$ \\
Aetiology of cirrhosis (ALD/PBC) & $8 / 0$ & $7 / 1$ \\
Child-Pugh score & $6.25(0.52)$ & $6.75(0.68)$ \\
$\quad$ Classification (A/B/C) & $5 / 3 / 0$ & $4 / 3 / 1$ \\
Portocaval pressure gradient & & $27.3(1.2)$ \\
$\quad$ Pre-TIPS (mm Hg) & $23.2(0.9)$ & $14.0(2.0)$ \\
Post-TIPS (mm Hg) & $13.8(1.4)$ &
\end{tabular}

ALD, alcoholic liver disease, PBC, primary biliary cirrhosis.

No significant differences between groups.

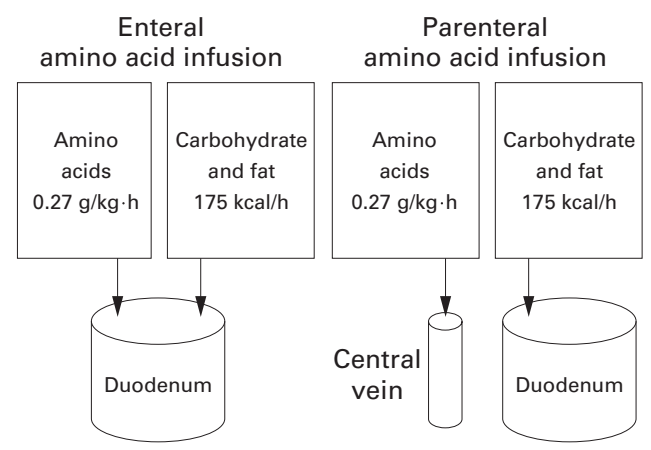

Figure 1 Experimental design of the infusion protocol. Infusions were performed from 0 to 120 minutes.

infusion of heparin was given at a rate necessary to prolong the activated prothrombin time to no more than twofold.

\section{NUTRITION PROTOCOLS}

All patients received a carbohydrate-fat mixture (Super Soluble Duocal, Scientific Hospitals Supply, Heilbronn, Germany) containing carbohydrate $182 \mathrm{~g} / 1$, fat $56 \mathrm{~g} / \mathrm{l}$, and $\mathrm{NaCl} 170$ $\mathrm{mmol} / \mathrm{l}$ via the nasoduodenal tube at a rate of $2.0 \mathrm{ml} / \mathrm{kg} / \mathrm{h}$ (equivalent to $175 \mathrm{kcal} / \mathrm{h}$ over 120 minutes). The mixture was given to provide caloric substrates and to maintain hormonal responses and mucosal perfusion comparable with the postprandial situation in both groups. In the enteral group $(n=8)$, this mixture also contained a glutamine fortified amino acid solution (Glamin, Pharmacia and Upjohn, Erlangen, Germany). This solution was chosen because of its high content of ammoniagenic amino acids glycine and glutamine. ${ }^{23}$ In the parenteral group $(n=8)$, an identical amino acid solution was infused via a central venous line at an identical rate (glutamine 274 $\mu \mathrm{mol} / \mathrm{kg} / \mathrm{h}$ ). Thus all patients received carbohydrate and fat isoenergetically by duodenal infusion while amino acids were given as an isonitrogenous infusion either by the enteral or parenteral route (fig 1). Patients were not allowed food or drinks other than plain water until the end of the study.

\section{BLOOD SAMPLING}

Blood was sampled in containers with either Li-heparinate (amino acids) or $\mathrm{K}_{2}$-EDTA (ammonia) in triplicate at baseline $(-10,-5$, and 0 minutes) and at $15,30,60,90,120,180$, and 240 minutes after the start of the infusion of nutrients. Sealed containers at $4^{\circ} \mathrm{C}$ were immediately transferred to the laboratory for centrifugation and deproteinisation (amino acids) or determination of ammonia. After deproteinisation, amino acid samples were kept at $-80^{\circ}$ until analysis.

\section{ANALYTICAL METHODS}

Ammonia was measured in plasma using an automated enzymatic test. ${ }^{24}$ Amino acid concentrations in plasma were measured by reversed phase high performance liquid chromatography with fluorescence detection after precolumn derivatisation with OPA. ${ }^{25}$ 

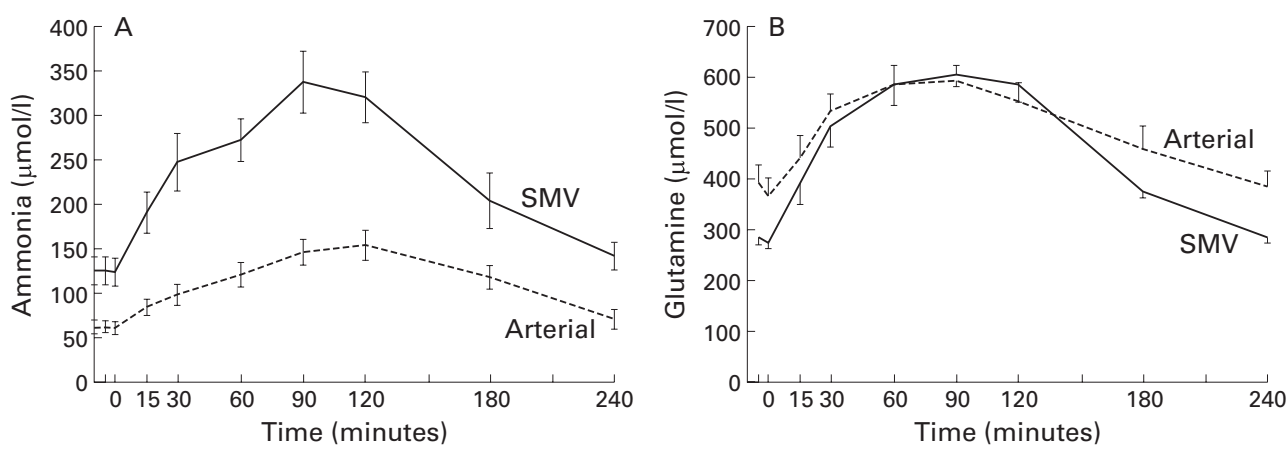

Figure 2 Enteral amino acid infusion. Ammonia (A) and glutamine (B) concentrations before, during (0-120 minutes), and after enteral infusion. Arterial and superior mesenteric venous (SMV) concentrations are mean (SEM).
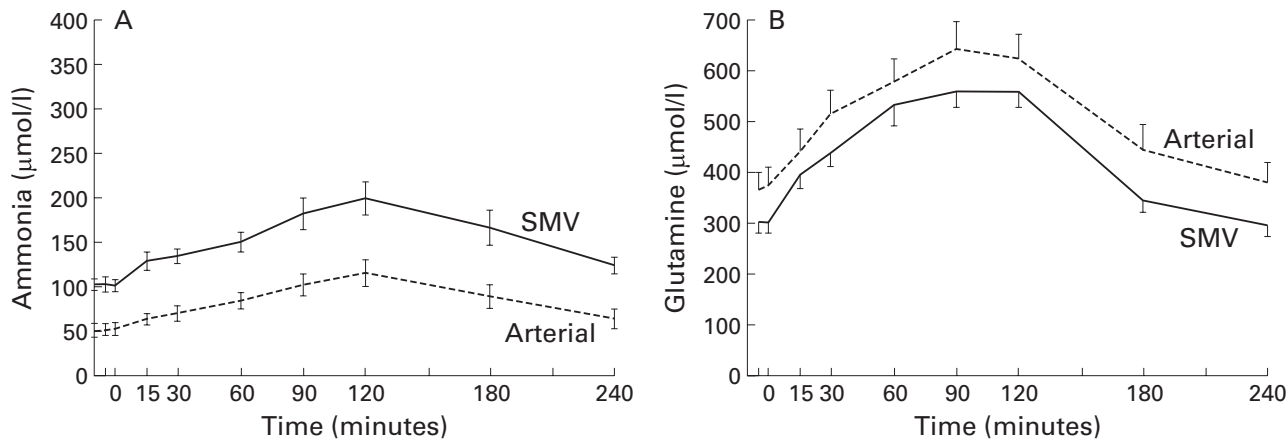

Figure 3 Parenteral amino acid infusion. Ammonia (A) and glutamine (B) concentrations before, during (0-120 minutes), and after parenteral infusion. Arterial and superior mesenteric venous (SMV) concentrations are mean (SEM).

CALCULATIONS AND STATISTICAL ANALYSIS

Substrate concentration differences were calculated as mesenteric venous-arterial concentration differences. Accordingly, negative values indicate net uptake and positive values net release. Substrate exchange was calculated as area under the curve of the venous-arterial differences for the baseline period and for 61-120 minutes of amino acid infusion. Systemic ammonaemia and glutaminaemia or portal availability and load were calculated as area under the curve of increments in arterial or mesenteric venous concentrations above baseline. All data are given as mean (SEM). Statistical significance was performed by two tailed $t$ test for paired or unpaired samples using Bonferroni's correction where appropriate. Venous-arterial differences were analysed for difference from zero using the two tailed Wilcoxon signed rank test for matched pairs. Data analysis was performed using Excel and SPSS on a personal computer. Results were regarded as significant at the 0.05 level.

\section{Results}

POST-ABSORPTIVE STATE

Before infusions of amino acids (AA), plasma levels of ammonia and glutamine in samples from the artery or mesenteric vein were not different between groups. However, the arterial ammonia level was elevated above normal (55 (3) $v 19$ (1) $\mu \mathrm{mol} / \mathrm{l} ; \mathrm{n}=16$ each; $\mathrm{p}<0.001$ ). Ammonia was released from the intestine with positive concentration differences between the superior mesenteric vein (SMV) and artery (61 (6) $\mu \mathrm{mol} / 1 ; \mathrm{p}<0.001)$. Glutamine was extracted by the intestine ( $\triangle \mathrm{SMV}$-arterial -91 (13) $\mu \mathrm{mol} / \mathrm{l} ; \mathrm{p}=0.003$ ), equivalent to a fractional extraction rate of $24 \%$.

EFFECT OF AMINO ACID INFUSION ON AMMONIA During enteral AA infusion, arterial ammonia levels increased from 60 (4) $\mu \mathrm{mol} / 1$ to maximal values of 157 (12) $\mu \mathrm{mol} / \mathrm{l}$ at 120 minutes $(\mathrm{p}<0.001)$ and returned to $74(7) \mu \mathrm{mol} / 1$ at 240 minutes (fig 2A). During parenteral AA infusion, however, there was a continuous but slow rise in arterial ammonia levels, reaching maximal values at 120 minutes (115 (12) $\mu \mathrm{mol} / \mathrm{l}$; $\mathrm{p}=0.036$ for parenteral $v$ enteral) (fig $3 \mathrm{~A})$. This resulted in a significantly $(p=0.033)$ higher degree of systemic hyperammonaemia during enteral than parenteral AA infusion (fig 4).

This increase in systemic hyperammonaemia was associated with a significant rise in mesenteric venous-arterial differences across

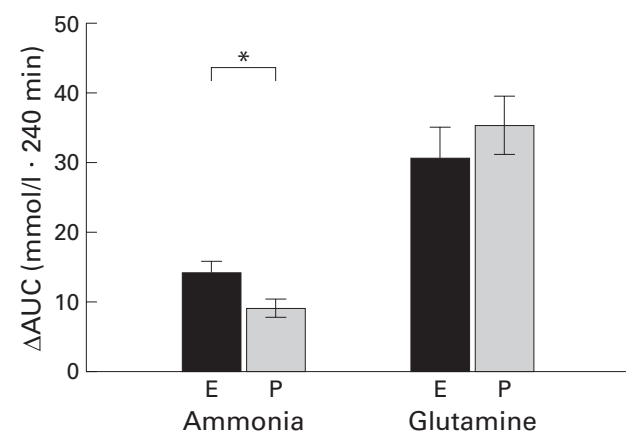

Figure 4 Degree of systemic hyperammonaemia and systemic availability of glutamine following enteral (E) or parenteral $(P)$ amino acid infusion. Values are calculated as area under the curve of increments in arterial substrate concentrations above baseline from 0 to 240 minutes. Error bars indicate SEM. ${ }^{\star} p<0.05$, enteral v parenteral. 

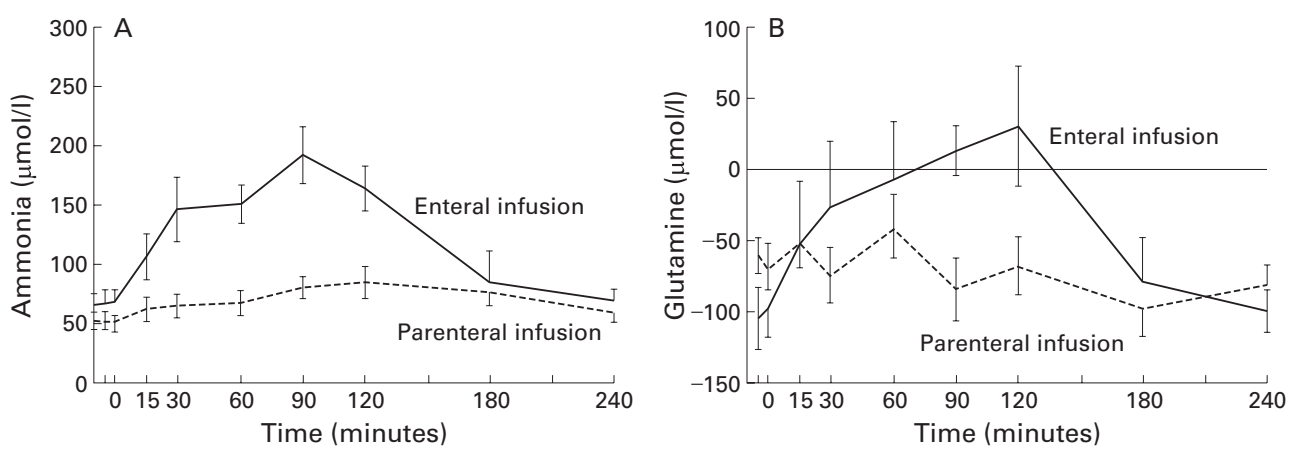

Figure 5 Concentration differences between the superior mesenteric vein (SMV) and artery during enteral or parenteral infusion of amino acids (0-120 minutes). Values are mean (SEM) for ammonia (A) and glutamine (B).
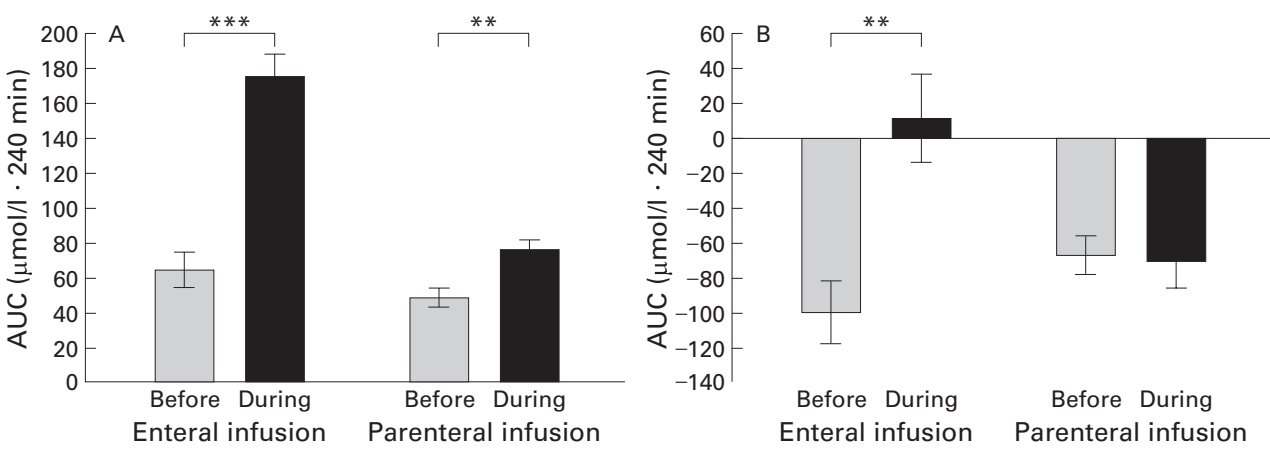

Figure 6 Intestinal exchange of ammonia (A) and glutamine (B) before and during the last 60 minutes of enteral or parenteral amino acid infusion, as calculated by the area under the curve method. Error bars indicate SEM. ${ }^{\star *} p<0.01$, $\star \star \star p<0.001$, before $v$ during infusion.

SMV drained viscera from 65 (9) to 107 (17) $\mu \mathrm{mol} / 1(\mathrm{p}=0.024)$ as early as 15 minutes after commencing enteral AA infusion (fig 5A). Mesenteric venous-arterial differences increased up to 166 (15) $\mu \mathrm{mol} / 1$ at 120 minutes. After the end of AA infusions, ammonia release declined to near basal levels $(70(7) \mu \mathrm{mol} / \mathrm{l})$ at 240 minutes. After parenteral AA infusion, however, ammonia release from SMV drained viscera increased only moderately from 50 (5) $\mu \mathrm{mol} / 1$ at baseline to 62 (8) $\mu \mathrm{mol} / 1$ at 15 minutes (NS), and to 85 (10) $\mu \mathrm{mol} / 1$ at 120 minutes $(\mathrm{p}=0.013)$ (fig $5 \mathrm{~A})$.

As a result, there was a significant increase in net intestinal ammonia efflux when baseline and the terminal infusion periods were compared during enteral $(\mathrm{p}<0.001)$ and parenteral $(p=0.009)$ AA infusions (fig 6A). However, the portal ammonia load was significantly $(p=0.0014)$ higher during enteral than parenteral AA infusion (fig 7).

EFFECT OF AA INFUSION ON GLUTAMINE

To search for possible alterations in the intestinal utilisation of glutamine as the major metabolic precursor of ammonia, glutamine concentrations were measured. Arterial and mesenteric venous glutamine levels increased promptly after enteral AA infusions were started (fig 2B). Simultaneously, the intestine ceased to extract glutamine from arterial blood and switched to release glutamine (mesenteric venous-arterial difference -100 (19) $\mu \mathrm{mol} / 1$ at baseline $v 31(40) \mu \mathrm{mol} / 1$ at 120 minutes; $\mathrm{p}=0.028)$. After enteral AA infusions were stopped, however, the intestine returned to extraction at 180 and 240 minutes (fig 5B).
After parenteral AA infusion, arterial levels of glutamine increased (370 (28) $v 628$ (41) $\mu \mathrm{mol} / 1$ at 120 minutes; $\mathrm{p}<0.001)$ to a similar degree as during enteral infusion (380 (28) $v$ 559 (29) $\mu \mathrm{mol} / 1$ at 120 minutes; $\mathrm{p}<0.01$ ) (fig 3B). Despite the increase in arterial levels during enteral AA infusion, the mesenteric venousarterial glutamine difference remained constant throughout (-66 (12) $v-68$ (18) $\mu \mathrm{mol} / 1$ at 120 minutes; NS).

During enteral infusions, intestinal net glutamine exchange changed from uptake to release $(p=0.008)$ but remained unaltered during parenteral infusion (fig 6B). Thus portal glutamine availability was higher $(p=0.048$ ) during enteral AA infusion (fig 7). Interestingly, the degree of arterial glutaminaemia, expressed as area under the curve of increments in arterial concentrations above

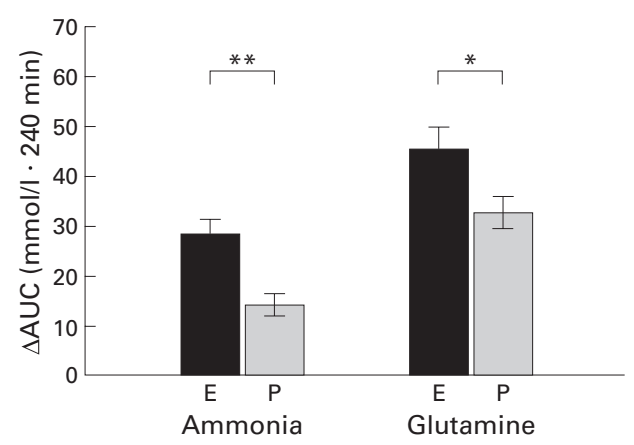

Figure 7 Portal ammonia load and portal availability of glutamine following enteral $(E)$ or parenteral $(P)$ amino acid infusion. Values are calculated as area under the curve of increments in mesenteric venous substrate concentrations above baseline from 0 to 240 minutes. Error bars indicate SEM. ${ }^{\star} p<0.05,{ }^{\star *} p<0.01$, enteral v parenteral. 
baseline, did not differ between the enterally or parenterally infused groups (fig 4).

\section{Discussion}

The beneficial effects of TIPS in the control of variceal haemorrhage or ascites ${ }^{12} 1326$ are associated with an increased risk of hepatic encephalopathy. ${ }^{14}$ We used TIPS to obtain mesenteric venous blood for selective measurement of intestinal ammonia release to study intestinal ammonia efflux and glutamine metabolism in the post-absorptive state, and during and after isonitrogenous enteral or parenteral infusion of amino acids.

Using this approach we obtained data supporting the view of the small intestine as a source of post-feeding hyperammonaemia in liver cirrhosis. Furthermore, in patients with cirrhosis and TIPS, enteral nutrition appeared to be associated with a higher degree of systemic hyperammonaemia than isonitrogenous parenteral nutrition. Finally, enteral and parenteral infusions of the same glutamine containing solution were associated with similar increases in arterial glutamine concentrations despite high first pass metabolism of glutamine in the intestine.

To verify the small intestine as a source of post-feeding hyperammonaemia, we chose a kinetic approach and measured ammonia efflux of SMV drained viscera after enteral or parenteral AA infusion. The rapid and significant increase in ammonia release from SMV drained viscera even at 15 minutes after commencing enteral AA infusions makes the small intestine the most likely site of this increase in mesenteric venous ammonia. This view is supported by the findings of van der Hulst and colleagues ${ }^{20}$ who demonstrated that glutamine uptake and ammonia release were much higher in the jejunum than in the ileum or colon. As no patient had abdominal symptoms or frank diarrhoea, and gastrointestinal transit may even be slowed as a result of sedation and cirrhosis, ${ }^{27}$ it is unlikely that the observed rapid increase could have resulted from colonic bacterial metabolism of infused nutrients. In addition, small intestinal bacterial overgrowth that may be present in patients with liver cirrhosis ${ }^{22}$ should have been eliminated by the decontamination protocol. The important findings of intestinal ammonia efflux and the degree of systemic hyperammonaemia being higher in the enteral than in the parenteral group were also confirmed when a separate analysis was performed for patients studied on the day of TIPS placement and those studied at elective TIPS portography.

Although we chose a substantial nitrogen load of $40.5 \mathrm{~g}$ of amino acids $/ 75 \mathrm{~kg}$ body weight within 120 minutes (analogous to protein test meals in cirrhotics ${ }^{28}$ ) none of our patients had worsening of their mental state and this has been confirmed in a subsequent study using psychometric tests. ${ }^{29}$ This finding merits particular attention as glutamine accounted for $5.9 \mathrm{~g}(14.5 \%)$ of the total amino acid load and has been regarded as more ammoniagenic than other amino acids and capable of inducing encephalopathy. ${ }^{23}{ }^{30}$ Our findings are in agree- ment with the observation that protein intolerant patients with cirrhosis and truly meal induced encephalopathy episodes are rather the exception than the rule and therefore protein restriction should be reserved for this minority of patients. ${ }^{15}$ In the light of our findings and a recent hypothesis, ${ }^{31}$ the question of glutamine as a potentially essential parenteral nutrient in malnourished cirrhotic patients deserves further clarification.

Interestingly, in terms of hyperammonaemia, parenteral amino acid infusion was clearly superior to enteral amino acid infusion in patients with cirrhosis, as shown by the significantly lower degree of arterial hyperammonaemia. This finding is even more remarkable considering that systemic availability of free glutamine, as measured by the degree of arterial glutaminaemia during enteral infusion, was no less than during isonitrogenous parenteral AA infusion. The potential for systemic hyperammonaemia may be expressed as a risk (hyperammonaemia)/benefit (glutaminaemia) ratio of the AUC of increments in arterial ammonia over the AUC of increments in arterial glutamine. Using this expression, parenteral AA infusion was associated with a lower risk/benefit ratio of $0.26(0.03) v 0.59$ (0.16).

The significant increase in systemic ammonia load during enteral AA infusion appeared to be a result of efficient intestinal first pass metabolism of glutamine and the fact that all administered glutamine must pass these straits before entering the systemic circulation; during parenteral infusion, glutamine is distributed to all tissues of the body. This may provide one explanation for the well known observation that parenteral nutrition using standard amino acids is generally well tolerated in patients with cirrhosis. ${ }^{15}$ Moreover, the difficulties of demonstrating an advantage of solutions enriched in branched chain amino acids compared with standard solutions ${ }^{32}$ may result from the low potential of standard solutions to cause arterial hyperammonaemia in control groups.

A second therapeutic implication of our findings concerns malabsorption or even small bowel evacuation as a likely common denominator regarding the mechanism of many different empirical strategies in the treatment of acute hepatic encephalopathy. Magnesium sulphate, sorbitol or disaccharides (among other modes of action) are potent osmotic laxatives. ${ }^{33}$ Neomycin in therapeutic doses has been shown to impair the structure and enzyme activity of enterocytes causing malabsorption. ${ }^{34}{ }^{35}$ Therefore, our data suggest that after gastrointestinal haemorrhage, blood should be cleared not only from the colon but also from the small intestine to remove this substrate for small intestinal metabolic ammonia generation ${ }^{36}$ and to avoid its unfavourable effect on intestinal protein metabolism. ${ }^{37}$

To our knowledge, this is the first study to measure amino acid absorption by assessment of mesenteric venous substrate activity in humans. Despite extensive metabolism by small intestinal enterocytes, a net mesenteric venous appearance of glutamine 
was demonstrated during the last 40 minutes of enteral AA infusion. Visual assessment of mesenteric venous-arterial concentration differences (fig 5A, B) suggests that glutamine uptake from the lumen was of the same magnitude as the increase in ammonia release from SMV drained viscera during enteral AA infusion. This impression is supported by calculating substrate net exchange using the area under the curve method for mesenteric venous-arterial concentration differences (fig 6). However, tracer studies are needed to draw more definite conclusions on the precise stoichiometry of ammonia production and glutamine consumption.

Interestingly, systemic availability of free glutamine and peak arterial levels were not different between groups. This finding indicates that, at least in patients with liver cirrhosis and portal systemic shunting, isonitrogenous infusion regimens produce similar systemic substrate availability regardless of the route of provision (enteral or parenteral).

Clearly, interpretation of our mesenteric venous-arterial difference data would be strengthened by a valid measurement of mesenteric venous blood flow, which at present is a technically unsolved problem, ${ }^{20}$ despite the availability of percutaneous ultrasound to estimate portal venous blood flow. ${ }^{38}{ }^{39}$ Using intravascular ultrasound measurements ${ }^{40}$ obtained from four patients in the present study, the calculated net exchange rates for glutamine $(-681$ (116) and -545 (93) $\mathrm{nmol} / \mathrm{min} / \mathrm{kg}$, enteral $v$ parenteral group; NS) and ammonia (575 (57) and $460(46) \mathrm{nmol} / \mathrm{min} / \mathrm{kg}$, enteral $v$ parenteral group; NS) in the post-absorptive state are in good agreement with data obtained in pigs or dogs. ${ }^{41-44}$ Although we cannot exclude the possibility that intestinal perfusion may have been different between the entire groups, this potential error was minimised as both groups received the same enteral carbohydrate and fat load to induce comparable changes in absorption induced mucosal perfusion and insulin response. Despite these limitations, the pronounced difference between groups in intestinal uptake or release of glutamine and intestinal release of ammonia clearly demonstrates that enteral AA infusion was associated with significant glutamine absorption and a greater increase in small intestinal ammonia efflux.

In conclusion, our findings support the hypothesis that in the absorptive state, glutamine metabolism of the small intestine is a source of increased portal ammonia concentrations and that post-feeding hyperammonaemia is caused, at least in part, by small intestinal ammonia release. Therefore, antihyperammonaemic strategies should take this into account, as exemplified by orthograde intestinal lavage. ${ }^{36}$ In cirrhotic patients with TIPS, enteral feeding may carry a higher risk of hyperammonaemia than parenteral feeding and should not be regarded as superior to parenteral feeding per se.

Cost of amino acid analyses were, in part, covered by a research grant from Pharmacia and Upjohn.
1 Wolpert E, Phillips SF, Summerskill WH. Ammonia production in the human colon. Effects of cleansing, neomycin and acetohydroxamic acid. $N$ Engl $f$ Med 1970;283:159-64

2 Sherlock S. Chronic portal systemic encephalopathy: Update 1987. Gut 1987;28:1043-8.

3 Nance FC, Batson RC, Kline DG. Ammonia production in germ-free Eck-fistula dogs. Surgery 1971;70:169-74.

4 Schalm SW, van der Mey T. Hyperammonemic coma after hepatectomy in germ-free rats. Gastroenterology 1979;77: 231-4.

5 Windmueller HG, Spaeth AE. Uptake and metabolism of plasma glutamine by the small intestine. $\mathcal{F}$ Biol Chem 1974; 249:5070-9.

6 Weber FL, Veach GA. The importance of the small intestine in gut ammonium production in the fasting dog. Gastroenterology 1979;77:235-40.

7 van Berlo CLH, van Leeuwen PAM, Soeters PB. Porcine intestinal ammonia liberation. Influence of food intake, 250-7.

8 Sugarbaker SP, Revhaug A, Wilmore DW. The role of the small intestine in ammonia production after gastric blood administration. Ann Surg 1987;206:5-17.

9 Plauth M, Raible A, Graser TA, et al. Lactulose or paromomycin do not affect ammonia generation in the isolated perfused rat small intestine. $Z$ Gastroenterol 1994; 32:141-5.

10 La Berge JM, Ring EJ, Gordon RL, et al. Creation of transjugular intrahepatic portosystemic shunts with the wallstent endoprosthesis: results in 100 patients. Radiology 1993;187:413-20.

11 Rössle M, Haag K, Ochs A, et al. The transjugular intrahepatic portosystemic stent-shunt procedure for variceal bleeding. N Engl F Med 1994;330:165-71.

12 Somberg KA, Lake JR, Tomlanovich SJ, et al. Transjugular intrahepatic portosystemic shunts for refractory ascites: assessment of clinical and hormonal and renal function. assessment of clinical and hort
Hepatology 1995, 21:709-16.

13 Ochs A, Rössle M, Haag K, Hauenstein K, et al. The transjugular intrahepatic portosystemic stent-shunt procedure

14 Nolte W, Wiltfang J, Schindler C, et al. Portosystemic hepatic encephalopathy after transjugular intrahepatic portosystemic shunt in patients with cirrhosis: Clinical, laboratory, psychometric, and electroencephalographic investigations. Hepatology 1998;28:1215-25.

15 Plauth M, Merli M, Kondrup J, et al. ESPEN guidelines for nutrition in liver disease and transplantation. Clin Nutr 1997;16:43-55.

16 Felig P, Wahren J, Räf L. Evidence of inter-organ amino acid transport by blood cells in humans. Proc Natl Acad Sci USA transport by blood

17 Owen OE, Reichle FA, Mozzoli MA, et al. Hepatic gut and renal substrate flux rates in patients with hepatic cirrhosis. f Clin Invest 1981;68:240-52.

18 Björkman O, Eriksson LS, Nyberg B, et al. Gut exchange of glucose and lactate in basal state and after oral glucose ingestion in postoperative patients. Diabetes 1990;39:74751 .

19 McAnena OJ, Moore FA, Moore EE, et al. Selective uptake of glutamine in the gastrointestinal tract: confirmation in a human study. Br f Surg 1991;78:480-2.

20 van der Hulst RR, von Meyenfeldt MF, Deutz NE, et al. Glutamine extraction by the gut is reduced in patients with depleted gastrointestinal cancer. Ann Surg 1997;225:112-
ditation 21 .

21 Plauth M, Roske A-E, Roth E, et al. Post-feeding hyperammonemia in liver cirrhosis is caused by small intestina ammonia production. Gastroenterology 1997;112:A1360.

22 Casafont F, de las Heras G, Martín L, et al. Small bowel bacterial overgrowth in patients with alcoholic cirrhosis. Dig Dis Sci 1995;40:1252-6.

23 Rudman D, Galambos J, Smith RB, et al. Comparison of the effect of various amino acids upon the blood ammonia concentration of patients with liver disease. Am f Clin Nutr 1973;26:916-25.

24 van Anken HC, Schiporst ME. A kinetic determination of ammonia in plasma. Clin Chim Acta 1974;56:151-7.

25 Roth E, Karner J, Ollenschläger G, et al. Alanylglutamine reduces muscle loss of alanine and glutamine in postreduces muscle loss of alanine and glutamine in post
operative anaesthetized dogs. Clin Sci 1988;75:641-8.

26 Jalan R, Forrest EH, Stanley AJ, et al. A randomized trial comparing transjugular intrahepatic portosystemic stentshunt with variceal band ligation in the prevention of rebleeding from esophageal varices. Hepatology 1997;26: rebleeding

27 van Thiel DH, Fagiuoli S, Wright HI, et al. Gastrointestinal transit in cirrhotic patients: effects of hepatic encephalopathy and its treatment. Hepatology 1994;19:67-71.

28 Staedt U, Leweling H, Gladisch R, et al. Effects of ornithine aspartate on plasma ammonia and plasma amino acids in patients with cirrhosis. A double-blind, randomized study using a four-fold crossover design. F Hepatol 1993;19:42430.

29 Jetschmann J-U, Söllner O, Schultz H, et al. Effects of an enteral nitrogen load on cerebral proton magnetic resonance spectroscopic findings in patients with liver cirrhosis. Clin Nutr 1999;18 (suppl):37.

30 Oppong KNW, Al-Mardini $\mathrm{H}$, Thick $\mathrm{M}$, et al. Oral glutamine challenge in cirrhotics pre- and post-liver transplantation: a psychometric and analyzed EEG study. Hepatology 1997;26:870-6. 
31 Teran JC, Mullen KD, McCullough AJ. Glutamine-a conditionally essential amino acid in cirrhosis? Am 7 Clin Nutr ditionally essential

32 Naylor CD, O'Rourke K, Detsky AS, et al. Parenteral nutrition with branched-chain amino acids in hepatic encephalopathy. A meta-analysis. Gastroenterology 1989;97:1033-

42 .

33 Conn HO, Lieberthal MM. Mechanism of action of lactulose. In: Conn HO, Lieberthal MM, eds. The hepatic coma syndromes and lactulose. Baltimore: Williams and Wilkins, 1978:278-94.

34 Dobbins WO III, Herrero BA, Mansbach CM. Morphologic alterations associated with neomycin induced malabsorption. Am ₹ Med Sci 1968;255:63-77.

35 Hawkins RA, Jessy J, Mans AM, et al. Neomycin reduces the intestinal production of ammonia from glutamine. Adv Exp Med Biol 1994;368:125-34.

36 Micklefield GH, Schwegler U, Hüppe D, et al. Orthograde Darmspülung mit einer Mannitlösung zur Reduktion der hepatischen Enzephalopathie bei Leberzirrhotikern mit hepatischen Enzephalopathie bei Leberzirrhotikern mit

gastrointestinaler Blutung. $Z$ Gastroenterol 1989;27:374-7.
37 van Berlo CLH, van de Bogaard EJM, van der Heijden MH, et al. Is increased ammonia liberation after bleeding in the digestive tract the consequence of complete absence of isoleucine in hemoglobin? A study in pigs. Hepatology 1989;10:315-23.
38 Delahunt TA, Geelkerken RH, Hermans J, Van Baalen JM, Vaughan AJ, Hajo van Bockel J. Comparison of trans- and intraabdominal duplex examinations of the splanchnic circulation. Ultrasound Med Biol 1996;22:165-71.

39 Iwao T, Tyonoga A, Shigemori H, et al. Echo-Doppler measurements of portal vein and superior mesenteric artery blood flow in humans: inter- and intraobserver short term reproducibility. F Gastroenterol Hepatol 1996;11:40-6.

40 Wruck U, Romaniuk P, Sha'ath B, et al. Estimation of TIPS blood flow by intravascular and percutaneous ultrasound. Gastroenterology 1998;114:A1366.

Gastroenterology 1998;114:A1366.
41 Souba WW, Wilmore DW. Postoperative alterations of arteriovenous exchange of amino acids across the gastrointestinal tract. Surgery 1983;94:342-50.

42 Cersosimo E, Williams PE, Radosevich PM, et al. Role of glutamine in adaptations in nitrogen metabolism during fasting. Am f Physiol 1986;250:E622-8.

43 Cersosimo E, Williams P, Geer R, Lairmore T, Ghishan F, Abumrad NN. Importance of ammonium ions in regulating hepatic glutamine synthesis during fasting. Am f Physiol 1989;257:E514-19.

44 Deutz NEP, Reijven PLM, Athanasas G, Soeters PB. Post-operative changes in hepatic, intestinal, splenic and muscle fluxes of amino acids ammonia in pigs. Clin Sci 1992;83:607-14. 